\section{Successful right atrial thrombus lysis with alteplase in a nine month old infant}

\author{
KRISTINA LAH TOMULIC • NEVEN FRLETA • NEVEN CACE • \\ JELENA ROGANOVIC • SREAN BANAC • VJEKOSLAV TOMULIC • \\ DAVID GOBIC
}

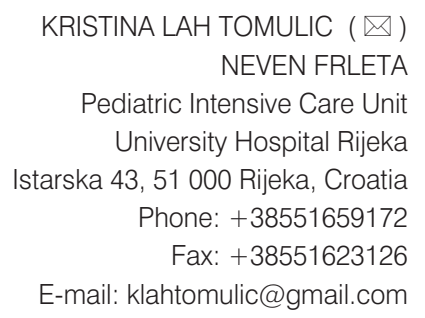

KRISTINA LAH TOMULIC ( $\square)$ NEVEN FRLETA

Pediatric Intensive Care Unit University Hospital Rijeka Istarska 43, 51000 Rijeka, Croatia Phone: +38551659172

Fax: +38551623126

E-mail: klahtomulic@gmail.com

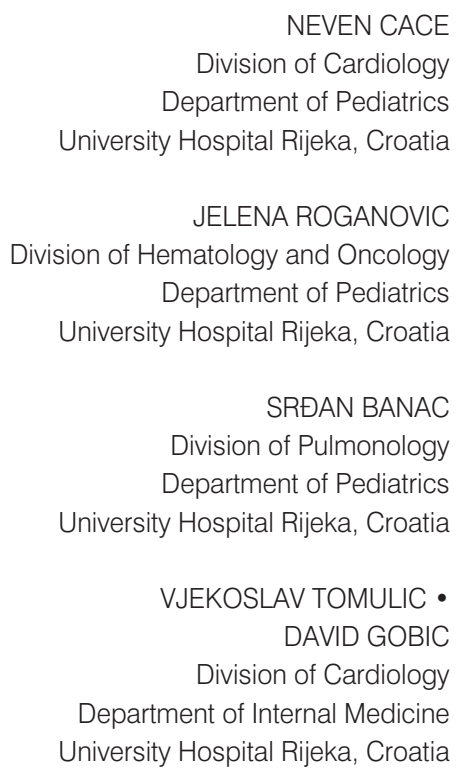

NEVEN CACE

Division of Cardiology

Department of Pediatrics

JELENA ROGANOVIC

Department of Pediatrics

University Hospital Rijeka, Croatia

Division of PUImonology

Department of Pediatrics

University Hospital Rijeka, Croatia

VJEKOSLAV TOMULIC •

DAVID GOBIC

Department of Internal Medicine

University Hospital Rijeka, Croatia

\begin{abstract}
Objective. To present the case of an infant with a catheter related atrial thrombus resolved with local instillation of alteplase. Clinical presentation. Echocardiography (ECHO) was performed in an infant with sepsis to estimate cardiac contractility, and a large mobile thrombus $(28 \times 8 \mathrm{~mm})$ was detected in the right atrium. A left subclavian, double lumen, central venous line (CVL, 4 French, $8 \mathrm{~cm}$ ), inserted 10 weeks previously, was left in place. Standard treatment with enoxaparine was commenced twice daily for 10 days at a dose of $1 \mathrm{mg} / \mathrm{kg}$. Repeat ECHO showed no changes in thrombus size or mobility. Therefore, alteplase was administered into the distal catheter (1 $\mathrm{mg}$ in normal saline) at a dose of $110 \%$ of its priming volume. The dwelling time was 2 hours. Since no changes in thrombus size were observed, the same dose was given into the proximal catheter. ECHO performed 24 hours later showed a significant reduction in thrombus size. The third dose of alteplase was administered into the proximal catheter. ECHO showed complete dissolution of the right atrial thrombus. No bleeding was observed during and following therapy, and there were no signs of hemodynamic instability. The CVL was safely removed the same day and no endoluminal thrombus was seen.

Conclusion. Local instillation of alteplase in three doses was a safe and effective approach to the management of a large catheter-related intraatrial thrombus. Systemic thrombolytic therapy, associated with an increased risk of bleeding, and open heart surgery were avoided.
\end{abstract}

Key words: right atrial thrombus, alteplase, fibrinolysis, central venous line, infant

\section{Introduction}

The care and treatment of children with acute or chronic diseases has been facilitated by the use of central venous lines (CVL). Partial or total occlusion of CVLs and catheter-related thrombosis are common complications. Catheterrelated thrombosis occurs more often in children with long-term CVLs (when even $50 \%$ of them can be asymptomatic). (1) The KIDCAT (Kids with CatheterAssociated Thrombosis) study showed that the incidence of thrombosis in children with short-term central venous 
catheters was $28 \%$ and $20 \%$ of them had clinical symptoms or had developed CVL occlusion. (2)

Formation of a right atrial thrombus in a child with a normal heart is rare. The presence of a CVL and systemic infection are the most important risk factors for the development of intraatrial thrombosis. If the thrombus is mobile, there is a significant risk of massive pulmonary embolism.

\section{Case report}

A 9-month old female infant was hospitalized in the Pediatric Intensive Care Unit because of an unclassified neuromuscular disorder. During the first few months of life echocardiography $(\mathrm{ECHO})$ was normal on several occasions.

After three weeks in hospital, acquired Klebsiella pneumoniae sepsis was diagnosed. A central line (4Fr, $8 \mathrm{~cm})$ was inserted through the left subclavian vein. Chest radiography showed that the tip of the line was correctly placed at the junction of the vena cava superior and right atrium. Two weeks later $\mathrm{ECHO}$ was performed to assess cardiac contractility and a large floating intraatrial mass was visualized (figure 1). There were no signs of hemodynamic compromise.

Platelet count and blood coagulation tests, including antithrombin III, were normal. D-dimer was slightly elevated (1.92 mcg/L). Magnetic resonance imaging of the heart showed that the intraatrial mass was a catheter-related intraatrial thrombus $28 \times 8 \mathrm{~mm}$ in size. The CVL was left in place and treatment with low-weight molecular heparin (enoxaparine) was initiated at a dosage of $1 \mathrm{mg} / \mathrm{kg}$ every 12 hours. ECHO performed after ten days of treatment with enoxaparine showed no signs of improvement. Cardiac surgeons were consulted, and treatment with tissue plasminogen activator (alteplase) was initiated. The risks of thrombolytic therapy were explained to the parents and informed consent was signed. The dose of alteplase was $110 \%$ of priming volume $(1 \mathrm{mg}$ in $1 \mathrm{~mL}$ of normal saline), and was administered into the distal catheter. The dwelling time was 2

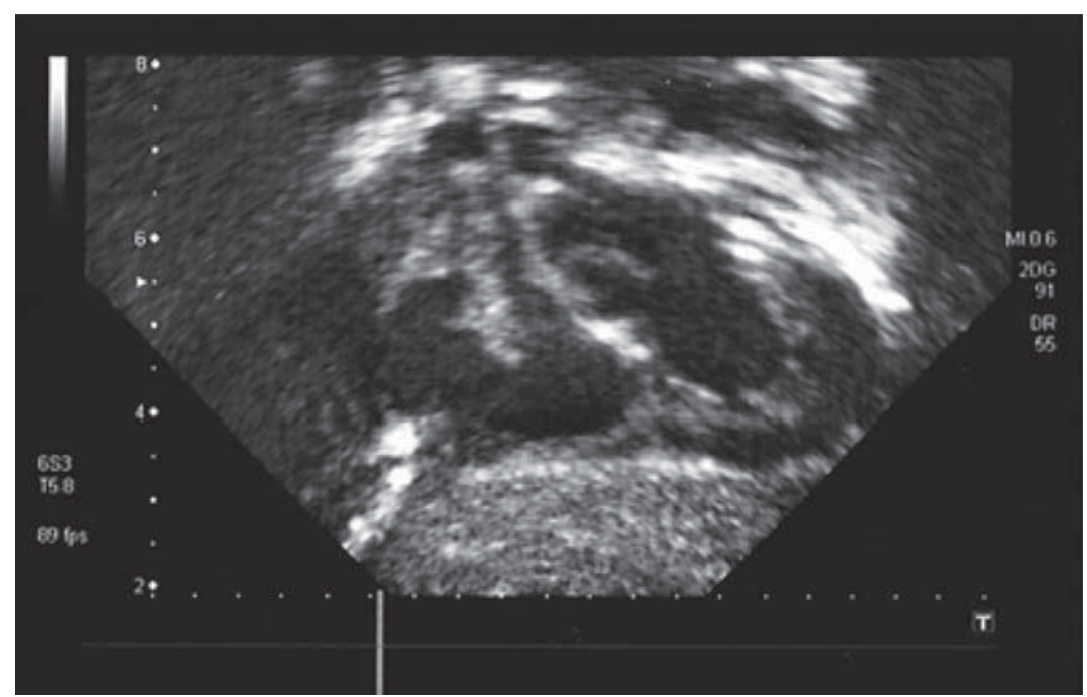

Figure 1. Echocardiography showed an intraatrial thrombus $(28 \times 8 \mathrm{~mm})$ before fibrinolytic treatment.

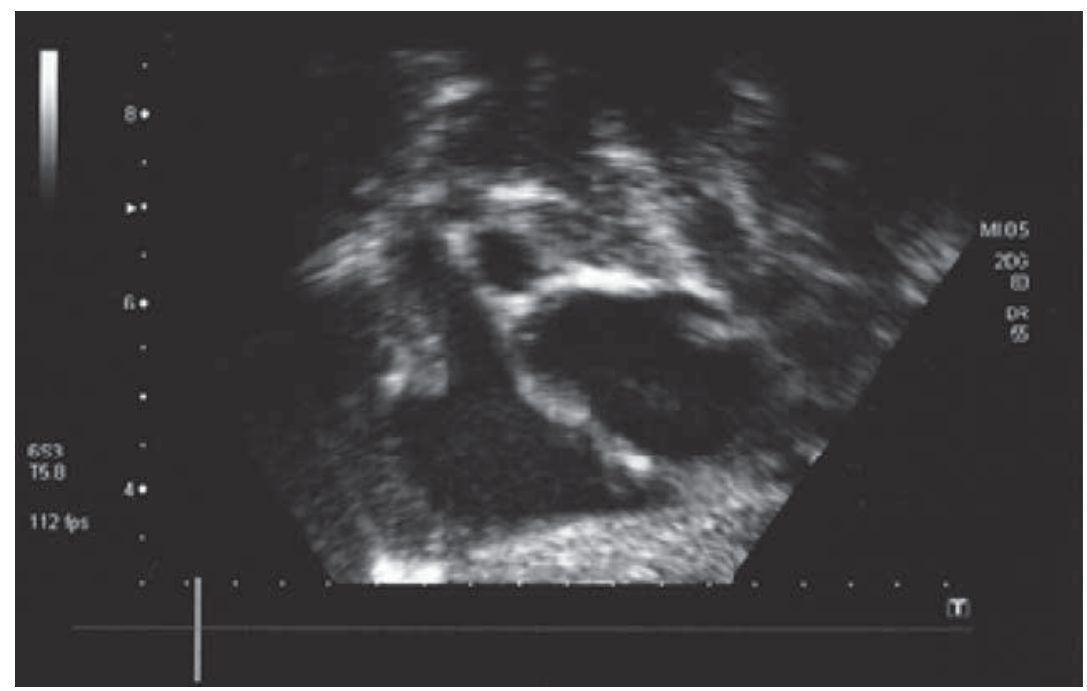

Figure 2. Complete dissolution of the intraatrial thrombus after the third dose of alteplase.

hours. Subsequent ECHO showed no changes in thrombus size, so a second dose of alteplase was administered into the proximal catheter. After another two hours, ECHO showed significant reduction in thrombus size. The third dose of alteplase was administered into the proximal catheter 24 hours later. After a dwelling time of 2 hours, ECHO revealed complete resolution of the thrombus (figure 2).

There were no signs of pulmonary embolism or bleeding during and following the fibrinolytic therapy. The CVL was safely removed. Factor V Leiden, factor II pro- thrombin and methylenetetrahydrofolate reductase (MTHFR) were all normal. Therapy with enoxaparine continued at a prophylactic dose $(0.5 \mathrm{mg} / \mathrm{kg}$ twice daily) for the next three months.

\section{Discussion}

There are no clear recommendations for a therapeutic approach to organized catheter-related intraatrial thrombi. The standard treatment for occluded CVLs is local instillation of alteplase with the maximum dose of $2 \mathrm{mg} / 2 \mathrm{~mL}$. When the volume of the catheter is less than $2 \mathrm{~mL}$, the recommended dose is $110 \%$ 
of its volume. (1) The COOL study (Cardiovascular thrombolytic used to Open Occluded Lines) showed that fibrinolysis with alteplase in adults and in children with obstructed CVLs is a safe and effective therapeutic procedure, with overall catheter clearance rates of $83-87 \%$ and no adverse outcomes documented. $(3,4)$ The Cathflow Pediatric Study Group reported that none of 310 patients under the age of 17 treated with local instillation of alteplase experienced intracranial hemorrhage. (5) Fibrinolytic activity of alteplase is based on its catalytic effect on the conversion of plasminogen into plasmin. Therefore, there are suggestions to give fresh frozen plasma before alteplase therapy in young infants and in cases of plasminogen deficiency. (6)

According to the evidence-based clinical practice guidelines of the American College of Chest Physicians, in regard to the most commonly used local and systemic dose regimens for thrombolytic therapy in pediatric patients, alteplase is the treatment of choice in patients who require fibrinolysis. (6)
Published series recommend alteplase infusion from low dose $(0.01 \mathrm{mg} / \mathrm{kg} / \mathrm{h})$ to high dose $(0.6 \mathrm{mg} / \mathrm{kg} / \mathrm{h})$, with the reported bleeding risk varying from 3 to $27 \%$. $(7,8)$ However, the optimum doses for children are not known. Successful treatment of a large intracardial thrombus using escalating tissue plasminogen activator infusions (0.1-0.25 $\mathrm{mg} / \mathrm{kg} / \mathrm{h}$ ) without bleeding complications has been reported. (9) There is also no evidence about the advantage of systemic over local thrombolytic therapy.

In this reported case, the intraatrial thrombus was large and organized. As the blood could not be aspirated from the catheter about two weeks before diagnostic $\mathrm{ECHO}$, we can speculate that the thrombus was present for at least a week. Since there were no signs of hemodynamic instability, treatment with low-weight molecular heparin was administered for ten days. When considering initial fibrinolytic therapy with alteplase, we preferred its local instillation rather than systemic infusion, because of less reported complica- tions. (6) Although a number of studies have reported a low incidence (modest benefit of $19 \%$ or less) of successful thrombus resolution after the second dose of local instillation of alteplase, $(5,10)$ in our case a significant reduction in thrombus size was observed. Furthermore, the third dose of alteplase resulted in complete dissolution of the thrombus.

\section{Conclusion}

The local instillation of alteplase in doses recommended for catheter obstruction was successful in management of a large, mobile catheter-related intraatrial thrombus. This seems to be a reasonable therapeutic option even if the thrombus is large and already organized. The dwelling time should be at least two hours with subsequent echocardiographic and hematologic assessment. If partial reduction of thrombus size is obtained after two doses of alteplase, the third dose could be effective. Thus, the high risk of bleeding, as a complication of systemic fibrinolytic therapy, seems to be avoidable.

\section{REFERENCES}

1. Baskin JL, Pui CH, Reiss U, Wilimas JA, Metzger ML, Ribeiro RC, et al. Management of occlusion and thrombosis associated with long-term indwelling central venous catheters. Lancet 2009 Jul 11;374(9684):159-69.

2. Hanslik A, Thom K, Haumer M, Kitzmüller E, Albinni S, Wolfsberger M, et al. Incidence and diagnosis of thrombosis in children with shortterm central venous lines of the upper venous system. Pediatrics 2008 Dec;122(6):1284-91.

3. Ponec D, Irwin D, Haire WD, Hill PA, Li X, McCluskey ER. Recombinant tissue plasminogen activator (alteplase) for restoration of flow in occluded central venous access devices: a double-blind placebo-controlled trial--the Cardiovascular Thrombolytic to Open Occluded Lines (COOL) efficacy trial. J Vasc Interv Radiol 2001;12(8):951-5.

4. Baskin JL, Reiss U, Wilimas JA, Metzger ML, Ribeiro RC, Pui CH, Howard SC. Thrombolytic therapy for central venous catheter occlusion. Haematologica 2012 May;97(5):641-50.

5. Blaney M, Shen V, Kerner JA, Jacobs BR, Gray S, Armfield J, et al. CAPS Investigators Alteplase for the treatment of central venous catheter occlusion in children: results of a prospective, open-label, single-arm study (The Cathflo Activase Pediatric Study). J Vasc Interv Radiol 2006 Nov; $17(11$ Pt 1):1745-51.

6. Monagle P, Chalmers E, Chan A, DeVeber G, Kirkham F, Massicotte P, et al. Antithrombotic therapy in neonates and children: American College of Chest Physicians Evidence-Based Clinical Practice Guidelines (8th Edition). Chest 2008 Jun;133(6 Suppl):887S-968S.

7. Gupta AA, Leaker M, Andrew M, Massicotte P, Liu L, Benson LN, et al. Safety and outcomes of thrombolysis with tissue plasminogen activator for treatment of intravascular thrombosis in children. J Pediatr 2001 Nov; 139(5):682-8.

8. Wang M, Hays T, Balasa V, Bagatell R, Gruppo R, Grabowski EF, et al; Pediatric Coagulation Consortium. Low-dose tissue plasminogen activator thrombolysis in children. J Pediatr Hematol Oncol 2003 May;25(5):379-86.

9. Mathur M, Desai N, Sharma J, Rao SP, Goldman GM. Management of a large organized intraatrial catheter-tip thrombus in a child with acquired immunodeficiency syndrome using escalating tissue plasminogen activator infusions. Pediatr Crit Care Med 2005 Jan;6(1):79-82.

10. Shen V, Li X, Murdock M, Resnansky L, McCluskey ER, Semba CP; COOL Investigators. Recombinant tissue plasminogen activator (alteplase) for restoration of function to occluded central venous catheters in pediatric patients. J Pediatr Hematol Oncol 2003 Jan;25(1):38-45. 